\title{
Hybrid Emergy-LCA (HEML) based metabolic evaluation of urban residential areas: The case of Beijing, China
}

\author{
Dong $\mathrm{Li}^{\mathrm{a}, \mathrm{b}}$, Rusong Wang ${ }^{\mathrm{a}, *}$ \\ a State Key Laboratory of Urban and Regional Ecology, Research Center for Eco-Environmental Sciences, The Chinese Academy of Sciences, 18 Shuangqing Road, Haidian, \\ Beijing 100085, China \\ ${ }^{\mathrm{b}}$ China Academy of Urban Planning and Design, 9 Sanlihe Road, Haidian, Beijing 100037, China
}

\section{A R T I C L E I N F O}

\section{Article history:}

Received 21 January 2008

Received in revised form 4 September 2009

Accepted 7 September 2009

Available online 8 October 2009

\section{Keywords:}

Emergy Analysis

Life Cycle Assessment

Urban metabolic evaluation

Residential area

Beijing

\begin{abstract}
A B S T R A C T
In this paper, metabolic evaluation has been employed for better understanding the trends in urban environmental changes. Due to the urban activities cause impacts not only on local level but also a broader scale, Hybrid Emergy-LCA (HEML), a combining approach of Emergy Analysis (EMA) and Life Cycle Assessment (LCA) is structured to quantitatively investigate the mechanism. For the similarity across many emerging cities in China, a large-scale sub-urban residential area named Tian Tongyuan (TTY) in Beijing was chosen for testing the HEML. Objective indicators of live quality and negative impacts are both considered. Analysis indicates that the household Emergy input of TTY is $1.76 \mathrm{E}+16 \mathrm{sej} /$ yr, while the prominent environmental impact is induced by Photochemical Oxidant Creation Potentials (POCP), $4.58 \mathrm{E}+05 \mathrm{~g}$ ethane eq./yr. The sustainable performance constructed by its live quality and environmental impacts of TTY is found as $98.80 \%$ as that of Beijing average. Mitigation polices on the building sector should be proposed because of its dominating impacts among various consuming ends of energy and materials.
\end{abstract}

(c) 2009 Elsevier B.V. All rights reserved.

\section{Introduction}

The global trends of urbanization have made urban regions the central factor in how resources are metabolized within the human society. According to the UN statistics (2006), the world urbanized rate has exceeded $45 \%$. This figure will continue growing to $61 \%$ around 2030. The world's urban population lives within geographic areas covering 2\% of the Earth's surface only. Many metabolic processes and functions are mainly located in urban configurations, such as, the production and consumption of large amount of non-renewable energy, excessive exploitation of raw materials, heavy pressures on surrounding environment to the point of exhaustion and high amounts and rates of waste discharged. Influenced by the seminal book, Our Common Future, cities have become an integral scale in the struggle to define and achieve sustainability (Clark, 2003).

One of the most uncertain terms in the pursuit of urban sustainability is how to measure the status or the progress at different spatial scales (Ryan et al., 2007). Due to the intimate relationship of environmental impacts, analysis on the direct and indirect impacts of cities requires further development of methodological techniques for assessing the societal metabolism

\footnotetext{
* Corresponding author. Fax: +86 1062943807.

E-mail addresses: uriel.li@gmail.com (D. Li), wangrs@rcees.ac.cn (R. Wang).
}

of energy and materials (Bai, 2007). Combing with the existing social complexity (Tainter, 2006), studies in urban metabolism have become an important instrument of sustainability since the groundbreaking work of Wolman (1965). Researches that followed began to focus on metabolic flows throughout the urban ecosystem (Decker et al., 2000; Zhang et al., 2006). In their cases, quantitative assessments were highlighted to present the total impacts derived from the socio-economic and technical progresses. All together, results from these studies clearly indicated that metabolic flows had remarkable influences on the urban sustainability (Kennedy et al., 2007).

The urban sustainability requires a way to evaluate the metabolic effects of urban residential areas (URAs). Investigating the sustainable performance of a specific URA will assist in understanding the urban metabolism dynamics and its implications for broader impacts. Herein two sub-topics exist. One is to evaluate the residential services occupied by the residents; another is to evaluate the gross environmental impact of the residential activities. For the first one, Quality of Life (QoL) of communities has been adopted in previous studies in the U.S.A., in the U.K. as well as in other E.U. countries (Costanza, 2007; Distaso, 2007; McMahon, 2002). The idea of QoL mainly focused on the social aspect of sustainability by surveying and measuring the subjective and psychological satisfaction of residents in URAs. For the aspect of gross environmental impact, some approaches have been developed to reveal the broader contents, such as Materials 
Flow Analysis (MFA) (Ritthoff et al., 2002), embodied energy analysis for buildings (Reddy and Jagadish, 2003; Thormark, 2002), and the modified Ecological Footprint (Ferng, 2005), etc. However, there is still much potential for improving metabolic indicators of "services" and "pressures" in URAs.

From the views of ecologists, negative impacts to ecosystems will not be alleviated unless a new energy budget of the biosphere and civilization is reestablished (Makarieva et al., 2008). By simplifying the complexity of the whole biosphere-human system, the Emergy Theory comes close as an appropriate tool for discussing the ecosystems services and pressures (Odum, 1996). Inherited from the food web theory, the core concept of Emergy Theory is to evaluate the natural and the man-made components (e.g. resources, commodities and services) and their metabolic flows (e.g. renewable and/or non-renewable energy flows) in terms of a common unit solar emjoule (sej). All the components in the metabolic system are accounted by tracing the renewable and non-renewable inputs during their production and procession, where the ultimate primary input of biosphere is solar energy. Emergy is usually referred to "energy memory" (Scienceman, 1997), for its feature of tracing the work done by the natural ecosystems. In this manner, Emergy Analysis (EMA) could be employed to look into the fundamental flows, which is pivotal to urban ecosystem studies.

EMA was founded on the principles of the second law of thermodynamics, system theory and systems ecology (Brown and Herendeen, 1996). A similar philosophy was also used to explore other problems in urban systems, such as economic process (Raine et al., 2006). By bridging the human behaviors and natural properties from a biophysical foundation, rather than the traditional monetary based methods or subjective value based methods, EMA evaluates the benefits and costs together. For the more Emergy inflows are utilized, the higher level of products/ services output is obtained, with correlative ecological pressures in return. Based on EMA, different issues in cities were investigated respectively, such as single buildings, building materials industry and urban land use (Huang et al., 2001; Meillaud et al., 2005; Pulselli et al., 2007). More discussions on thermodynamics and ecosystems have been published (Dincer and Rosen, 2005; Jogensen and Fath, 2004; Ludovisi et al., 2005; Rosen, 2002), which suggested the thermodynamics based approaches like EMA could tell a good story when studying the characters of systems as well as its environmental impacts, and prove useful to decision makers as well as scientists.

However, some studies point out the EMA method does not give enough consideration to the impacts of pollutants emission (Hau, 2002). This is not a flaw of Emergy Theory, because it is derived from natural ecosystems, and there are no wastes in natural ecosystems, becoming used as the materials for some other processes. The longterm co-evolving mechanism allows the temporal disturbance of wastes to be harmonized. However, the current economic and technical conditions of urban systems cannot satisfy the needs for reusing all anthropogenic pollutants ideally. Thus we also introduce Life Cycle Analysis (LCA), the major tool of Industrial Ecology, as a supplementary environmental index to demonstrate the gross impacts of target systems. Compared with many greenhouse gas emission indicators (Pataki et al., 2009), LCA provides more kinds and contents of the essential impacts, especially on different spatial scales. Ulgiati et al. (2006) argues that life-cycle environmental impact belongs to the downstream impact indicators, while the broader EMA locates more upstream. In a similar framework, developed in Bai (2007), the complementary emphasis between EMA and LCA encouraged researchers to make contributions towards a new synthesized approach, linking the regional-oriented EMA with the product-oriented LCA (Ness et al., 2007). Some efforts have been done. For example, Pizzigallo et al. (2008), and Raugei et al. (2005) presented their analysis results of EMA and LCA indicators together but separately. Brown and Buranakarn (2003) provided an LCA-like EMA by adding the product's Emergy of different processing phases from bottom up. This synthesized approach was adopted here to draw a clearer picture of URAs.

According to the features of URAs, we structured a new joint way, called the Hybrid Emergy-LCA (HEML) method, employing EMA for evaluating the end-uses of household services received by residents (including buildings, appliances and vehicles), as well as the ecological pressures of URA systems. LCA inventory results are used for presenting the mass of pollutants and the gross environmental impacts induced by these household services. Lastly, a synthesized indicator called the Emergy margin of environmental impact is defined to reveal the amount of annual Emergy inflows per gross environmental impact of URAs.

China is currently under excessive ecological and environmental pressures from the effects of rapid urbanization. Material and energy demands are both increasing dramatically together, which implies that the cities in China will not be escaping shortages of resources if the urbanized rate follows the current trend (Shen et al., 2005). As the capital, Beijing is experiencing an intensive urban sprawling coupled with its economic growth in the past decades. The URAs in Beijing are moving outwards due to the limited space in the inner city and higher costs of land. Several URAs are planned to host hundreds of thousands residents. The immigrating population and the changing social values on URAs are major forces supporting the rigid housing demand (Janssen, 2007). The local and regional environmental qualities are consequently detrimentally affected by the large amount of construction and heavy commuting traffic, for instance, poor air quality and urban heat island effects are found both exacerbated by Chan and Yao (2008) and Xiao and Ouyang (2007). Making decisions of mitigation requires comprehensive understanding and evidences of the baseline of URAs in Beijing and relevant issues.

The significance of this paper derives from a more interactive way of combining the use of EMA and LCA, applying it to the metabolic evaluation of URAs. The integrated approach provides useful information to the governance for the rapidly sprawling city of Beijing.

This paper develops the relevancy of the HEML method in the following manner. Section 2 instructs the general methods of EMA and LCA and their integration. The HEML indices are proposed for evaluating urban residential area comprehensively. Sections 3 and 4 present a recent case study located in Beijing for illustrating how this framework works, and also includes the methods of how the data was prepared and calculated. Relative results are also discussed. Section 5 offers a comparison study with the average conditions in Beijing. Finally, a summary of primary findings on the proposed HEML method is provided in Section 6.

\section{Methods}

\subsection{Emergy Analysis (EMA)}

The general framework of EMA has been explained in the series of handbook by Odum et al. (2000) and was further elaborated in a variety of other publications (Bargigli and Raugei, 2004; Brown and Ulgiati, 2002). Here is a brief summary of major steps in applying the EMA framework, including:

- Defining the system boundary, is primarily required. Particularly, to obtain a well integrated result, the boundary of EMA should be set accordingly with the LCA scope (see Fig. 1). For the cases of URAs, buildings, appliances and vehicles are covered, as well as their phases of producing, processing and discharging. The targeted URAs are monitored for the flows of energy and material of each component's inputs and outputs. The indirect output, 


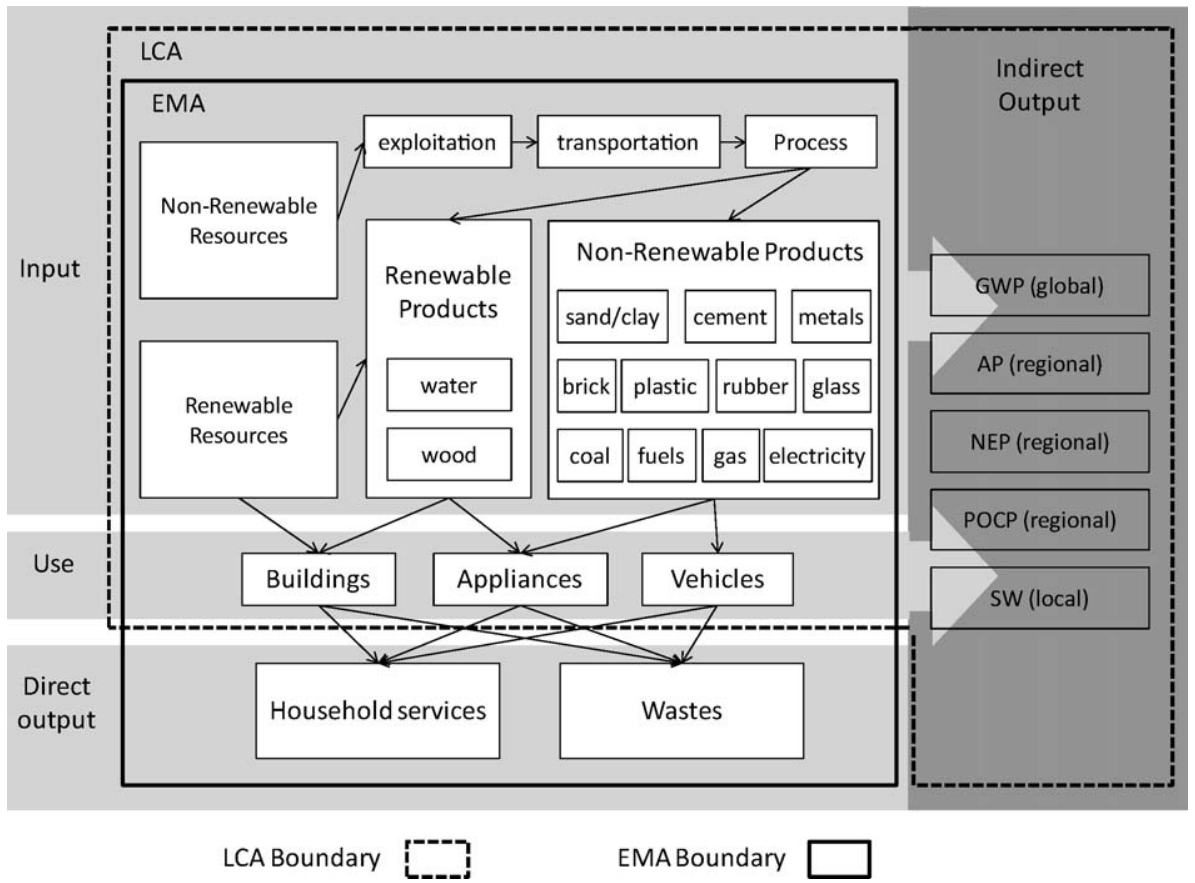

Fig. 1. Boundaries of URA metabolic system and involved components.

environmental impacts of major pollutants, are discussed in Section 4.2.

- Drawing a systems flow chart, allows for organizing relationships between components and pathways of resource flows. Within the rectangular frame of the system, the sources, components, and flows are drawn with the Emergy language symbols (Table 1). The left-right order expresses a hierarchy of energy quality (containing more sej per unit). For URAs, the main streams include local renewable inputs, purchased energy (feedback from economy system), total input (utilization, where $\mathrm{U}=\mathrm{F}+\mathrm{R}$ ) and waste. All the Emergy flows are defined as a product of their actual energy and transformities (a specific Emergy rate of energy or materials).
- Calculating annual Emergy (empower) tables, the aggregative table is structured from the flows chart, where each input flow becomes a row in the table to be evaluated. The references of Transformities and percentages are also listed in columns.

- Emergy indicators are evaluated, using the indicators for systematically investigating the output and the pressures of the targeted URAs (Table 2).

\subsection{Life Cycle Assessment (LCA)}

The LCA method is mainly used for studying the total resources needed and the total emissions output of producing processes. However, by enlarging the scope of LCA, the use phase of

Table 1

Major system symbols and their short descriptions.

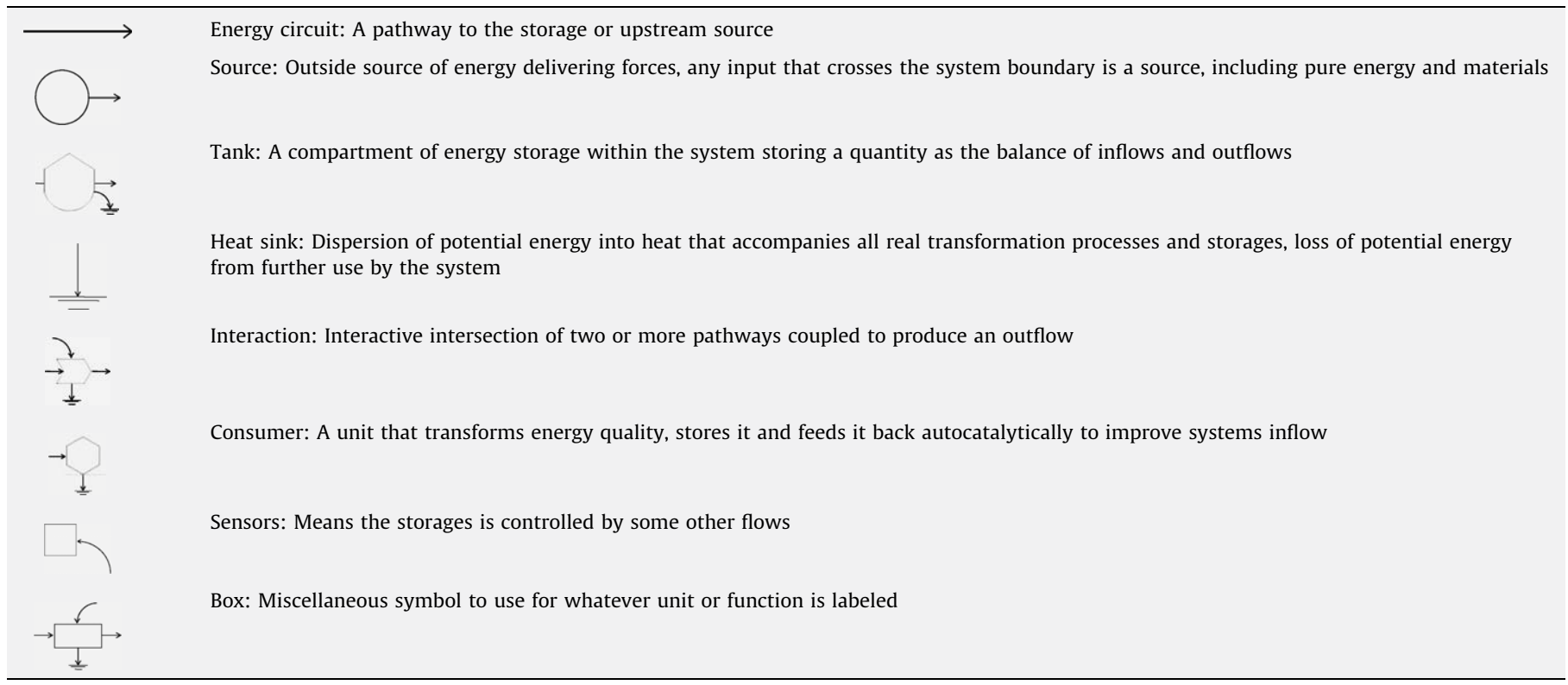


Table 2

Emergy indicators and explanations.

\begin{tabular}{|c|c|c|c|}
\hline & Expression & Unit & Explanations \\
\hline Household empower & U/households & sej/yr & Average Emergy inflow per household, an objective indicator of residential living quality \\
\hline URA environmental load ratio (ELR) & $\mathrm{F} / \mathrm{R}$ & $\mathrm{N} / \mathrm{A}$ & $\begin{array}{l}\text { The ratio of purchased non-renewable resources to local supporting capability, an inflow } \\
\text { indicator of the URA system pressure on local ecosystem }\end{array}$ \\
\hline URA waste ratio (WR) & $\mathrm{W} / \mathrm{R}$ & $\mathrm{N} / \mathrm{A}$ & $\begin{array}{l}\text { The ratio of direct discharging wastes to local supporting capability, an outflow indicator } \\
\text { of the URA system pressure on local ecosystem }\end{array}$ \\
\hline
\end{tabular}

production could also be covered. It is important to construct a uniform system boundary similar as that of EMA.

The detailed instruction of LCA could be found from SETAC (Kotaji and Schuurmans, 2003), EPA (USEPA, 2006) and the ISO standards (ISO 14040, 1997). Usually, the LCA methodology can be synthesized in the following phases:

- Phase 1: Life Cycle Scoping, during this phase, in addition to defining the boundary of LCA, the Functional Unit (F.U.) also needs to be identified and confirmed. The F.U. is offering a reference unit to which the inputs and outputs of the metabolic system can be correlated. Thus the F.U. of URAs is considered to be affiliated with the EMA indicator of household empower (Table 2). This is another guarantee for constructing a uniform boundary.

- Phase 2: Life Cycle Inventory, details computing the relevant inputs and outputs of a producing system, including the required energy and materials as well as the discharged emissions. The production system is modeled as assemblage of single operations from cradle to grave. The amounts of the resources and the emissions are objectively expressed in units of mass.

- Phase 3: Life Cycle Assessment and interpretation, requires that the calculated inventory results be classified into specific impact categories for representing their significance of potential environmental impacts. The level of depth, the choice of evaluating methods (e.g. reference choosing, weighing and so on) are both dependent on the scope and goal set up at phase 1 . One of the criticisms of the LCA is derived from the subjectivity existing at phase 3 (Bakshi, 2002). The changes of technology, the broader environmental quality and the LCA scoping are all affecting, while the physical amounts of pollutants are much more comparable among different research cases. Nevertheless, after normalization, the integrated result helps judging the order of pollution migrating acts and visualizing them to decision-makers. It also makes sense for comparing cases within a similar spatio-temporal range. Thus, in HEML, we balanced the different demands. These two approaches are both adopted: the masses of major pollutants from inventory analysis and their normalized value after interpretation. A study of local references of these pollutions and their weighing factors is introduced to convey their relative impacts, which was finished by Yang et al. (2002). Pollutant impacts are divided into 5 categories: Global Warming Potentials (GWP), Acidification Potentials (AP), Nutrient and Eutrophication potentials (NEP), Photochemical Oxidant Creation Potentials (POCP) and Solid Waste (SW) (Table 3).

\subsection{Hybrid Emergy-LCA (HEML) index}

As discussed in Section 1, 5 aspects of the URA metabolic system are inspected besides a synthesized one. They are: (1) Emergy inflow per household provided from the URA system and even from the broader urban ecosystems, (2) the upstream and (3) the downstream impacts of the URA system and (4) the annual gross emission impact per household, and the (5) synthesized indicator, Emergy margin environmental impact for checking the household metabolic sustainability. It is defined as the household annual received Emergy (empower) per unit of household emission impacts (Table 4).

\section{Study area and data preparation}

\subsection{The targeted URA in Beijing}

Tian Tongyuan (TTY) residential area is located in the northern part of Beijing City, in a distance of $17.6 \mathrm{~km}$ away from the inner part (Fig. 2). The construction of this area began in the late 1990s. About $70 \%$ of the buildings are high-rises, while the rest consist of 6-8 stories. One of the major purposes of TTY was to provide more low-price apartments for local citizens. Now a population of 150,000 people is living in four sub-zones now (Table 5), which is expected to reach 300,000 in next 10 years.

\subsection{Data collection and development}

The social-economic and technical conditions of metabolic system in TTY are used for preparing primary data for the HEML method. The metabolic flow $M_{h}$ of the household $h$ is defined as:

$$
\begin{aligned}
M_{h}= & \sum_{j} \sum_{k} \text { life style }_{j, k} \times \text { product parameters }_{j, k} \\
= & \sum_{j} \sum_{k}\left(\text { own rate }_{j, k} \times \text { use intensity }_{j, k}\right) \\
& \times \text { product parameters }_{j, k}
\end{aligned}
$$

where $j=$ (buildings, appliances, vehicles) and $k$ means the major energy using products (EuP), such as air conditionings, water heaters and private cars, etc. A survey was carried out to collect the necessary life style information in 2005 (Li et al., 2009). The data of building materials in TTY was calculated from the local planning report and previous literature (Liu and $\mathrm{Hu}, 2006$ ).

Beside the high-density settlement, the residents in TTY were also suffering from bad traffic planning in this area. Though most of

\begin{tabular}{|c|c|c|c|c|}
\hline \multirow[t]{2}{*}{ Environmental impacts } & \multirow[t]{2}{*}{ Unit } & \multirow[t]{2}{*}{ Scale } & \multicolumn{2}{|c|}{ Normalization and weighting parameters } \\
\hline & & & Reference values in Beijing & Weighting factors \\
\hline Global Warming Potentials (GWP) & $\mathrm{g} \mathrm{CO}_{2}$ eq./yr & Global & $8700,000 \mathrm{~g} \mathrm{CO}_{2}$ eq./cap/yr & 0.83 \\
\hline Acidification potentials (AP) & $\mathrm{g} \mathrm{SO}_{2}$ eq./yr & Regional & $35,000 \mathrm{~g} \mathrm{SO}_{2}$ eq./cap/yr & 0.73 \\
\hline Nutrient and eutrophication potentials (NEP) & $\mathrm{g} \mathrm{NO}_{3}{ }^{-}$eq./yr & Regional & $59,000 \mathrm{~g} \mathrm{NO}_{3}{ }^{-}$eq./cap/yr & 0.73 \\
\hline Photochemical oxidant creation potentials (POCP) & g ethane eq./yr & Regional & $650 \mathrm{~g}$ ethane eq./cap/yr & 0.61 \\
\hline Solid waste (SW) & $\mathrm{g} / \mathrm{yr}$ & Local & $291,000 \mathrm{~g} / \mathrm{cap} / \mathrm{yr}$ & 0.62 \\
\hline
\end{tabular}

Table 3

Classification of household life cycle inventory of URAs. 
Table 4

HEML index of URAs.

\begin{tabular}{lll}
\hline Indices & Name & Unit \\
\hline X1 & Household empower & sej/yr \\
X2 & URA environmental & N/A \\
& load ratio (ELR) & N/A \\
X3 & URA waste ratio (WR) & g pollutant $\mathrm{i}_{\mathrm{i}}$ eq./yr \\
X4 & Gross household emissions & household sej/household \\
X5 & Emergy margin & emission impacts \\
& environmental impact &
\end{tabular}

Note: where $\mathrm{i}=\mathrm{CO}_{2}$ eq., $\mathrm{SO}_{2}$ eq., $\mathrm{NO}_{3}{ }^{-}$eq., ethane eq., solid waste.

their jobs were located in the inner city, the current roads and public transport lines were far behind in meeting the increasing demands of commuting. Costly time delays, air pollution, and other issues were induced by serious congestion. The transportation behavior of residents was also given significant attention in this study.

\section{Result}

\section{1. $E M A$}

After the survey, the basic energy and materials is accounted (column "input" in Table 6). The dynamic metabolism in real life is expressed by a year-by-year steady process. With the equation in Section 3.2, the energy and the materials used for every equipment are calculated and allotted within their life-spans averagely. Related Emergy values of metabolic flows are obtained by their input and transformities.

Fig. 3 shows the annual Emergy flow chart in TTY. The renewable and non-renewable inputs were $8.49 \mathrm{E}+18$ and $1.05 \mathrm{E}+21 \mathrm{sej} / \mathrm{yr}$ respectively. Hereinto, a flow of $9.93 \mathrm{E}+20 \mathrm{sej} / \mathrm{yr}$ Emergy was used for the parts of buildings and public, including
Table 5

Specifications of TTY.

\begin{tabular}{lll}
\hline Average household size & 2.46 & People \\
Number of households & 61,869 & Household \\
Population & 152,198 & People \\
Floor areas & 4426239.70 & $\mathrm{~m}^{2}$ \\
Covered area & 3512888.50 & $\mathrm{~m}^{2}$ \\
Low-rise:high-rise & $0.29: 0.71$ & \\
\hline
\end{tabular}

$2.32 \mathrm{E}+20 \mathrm{sej} / \mathrm{yr}$ for the home appliances. The rest of $9.79 \mathrm{E}+19 \mathrm{sej} /$ yr Emergy was used for the part of transportation. A sum of $1.09 \mathrm{E}+21 \mathrm{sej} / \mathrm{yr}$ Emergy was offered by the URA metabolic system to more than 60,000 households living in TTY.

Table 6 describes the breakdown Emergy flows supporting the local residents. Among these are the flows of renewable and nonrenewable inputs. The renewable inputs only account for $0.78 \%$ of total Emergy input, which is an obvious characteristic of an area relying on the external resources instead of products procured locally. Among the major non-renewable inputs, $41.20 \%$ are raw materials and $58.17 \%$ are fuel-bearing materials. Among the nonrenewable inflows, $68.46 \%$ is occupied by building and space heating, 22.06\% for appliances and 9.48\% for vehicles. For the use phase, the largest single Emergy inflow is coal for TTY URA's regional space heating use, $33.28 \%$ of the total utilized Emergy. Following that is electricity, $14.87 \%$, which is mainly used for the appliances and public facilities.

\section{2. $L C A$}

The LCA inventory of household consumption is listed as the indicator $\mathrm{X}_{\mathrm{i}}$ in Table 7. The normalized result in Fig. 4 indicates that the largest environmental impact is derived from the POCP pollutants. The amount of Household POCP is $4.67 \mathrm{E}+05 \mathrm{~g}$ ethane eq./yr. The products manufacturing and fuels using are major

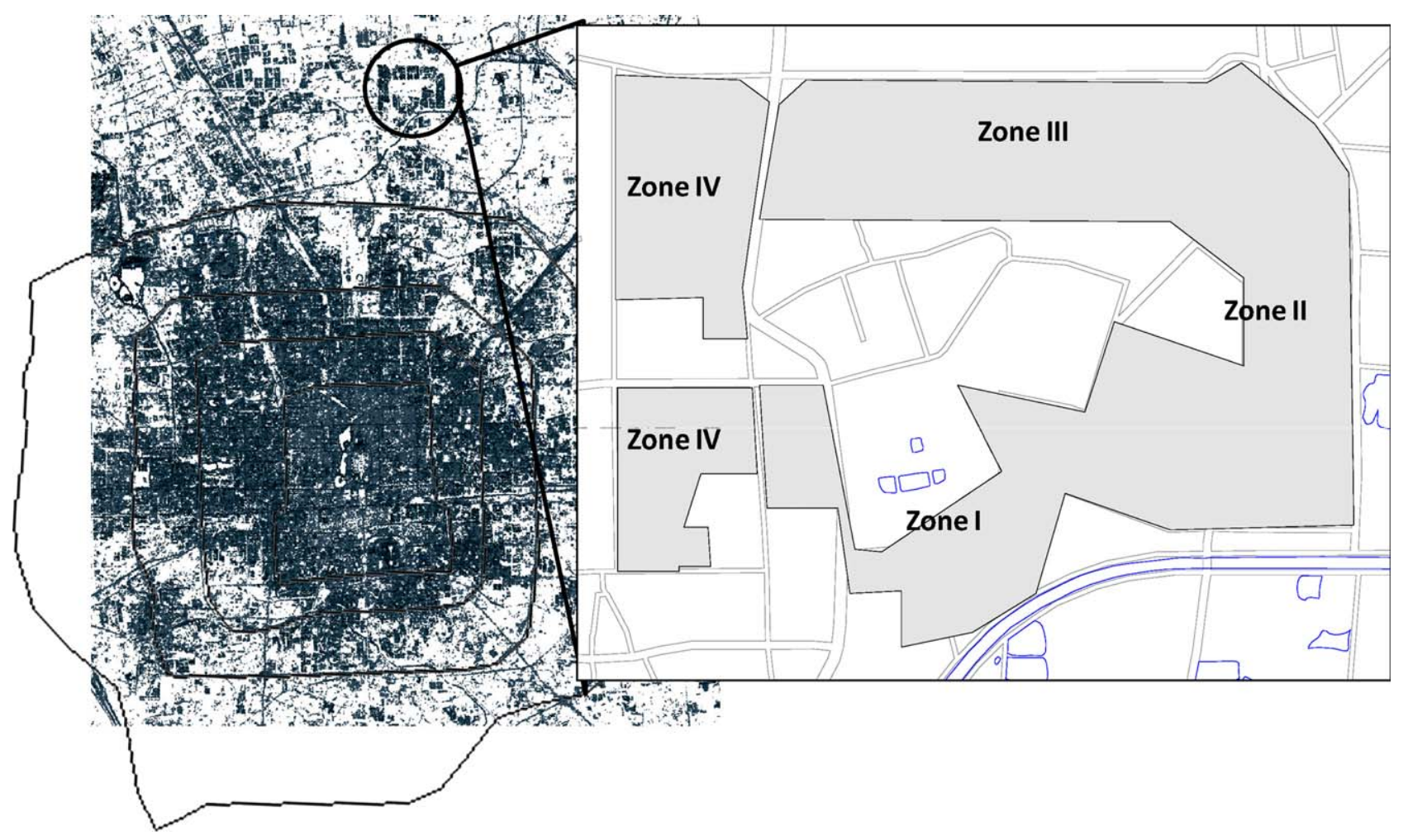

Fig. 2. Location and configuration of Tian Tongyuan (TTY). 
Table 6

Aggregated Emergy flow table of TTY.

\begin{tabular}{|c|c|c|c|c|c|c|c|}
\hline Note & Item & Input & Unit & Transformity (sej/unit) & Emergy flow (sej/yr) & Fraction (\%) & Ref. \\
\hline \multicolumn{8}{|c|}{ Renewable inputs } \\
\hline 1 & Sunlight & $2.35 \mathrm{E}+16$ & $\mathrm{~J}$ & $1.00 \mathrm{E}+00$ & $2.35 \mathrm{E}+16$ & 0.002 & Def. \\
\hline 2 & Wind & $3.32 \mathrm{E}+15$ & $\mathrm{~J}$ & $2.45 \mathrm{E}+03$ & $8.14 \mathrm{E}+18$ & 0.771 & a. \\
\hline 3 & Rain & $1.04 \mathrm{E}+13$ & $\mathrm{~J}$ & $3.10 \mathrm{E}+04$ & $3.23 \mathrm{E}+17$ & 0.031 & a. \\
\hline \multicolumn{8}{|c|}{ Purchased non-renewable input } \\
\hline 4 & Water & $3.16 E+13$ & $\mathrm{~J}$ & $8.06 \mathrm{E}+04$ & $2.55 \mathrm{E}+18$ & 0.241 & a. \\
\hline 5 & Wood & $2.05 \mathrm{E}+03$ & $\mathrm{t}$ & $1.48 \mathrm{E}+15$ & $2.88 \mathrm{E}+18$ & 0.273 & b. \\
\hline 6 & Sand & $5.03 \mathrm{E}+04$ & $\mathrm{t}$ & $1.12 \mathrm{E}+15$ & $5.37 \mathrm{E}+19$ & 5.080 & a. \\
\hline 7 & Stone & $9.01 \mathrm{E}+04$ & $\mathrm{t}$ & $1.68 \mathrm{E}+15$ & $1.44 \mathrm{E}+20$ & 13.637 & a. \\
\hline 8 & Iron & $1.76 \mathrm{E}+03$ & $\mathrm{t}$ & $4.75 E+15$ & $8.38 \mathrm{E}+18$ & 0.793 & c. \\
\hline 9 & Steel & $9.25 E+03$ & $\mathrm{t}$ & $6.97 \mathrm{E}+15$ & $6.24 \mathrm{E}+19$ & 5.902 & c. \\
\hline 10 & Aluminum & $3.40 \mathrm{E}+02$ & $\mathrm{t}$ & $2.11 \mathrm{E}+16$ & $7.16 \mathrm{E}+18$ & 0.678 & b. \\
\hline 11 & Copper & $2.49 \mathrm{E}+02$ & $\mathrm{t}$ & $1.14 \mathrm{E}+17$ & $2.83 \mathrm{E}+19$ & 2.675 & d. \\
\hline 12 & Cement & $2.12 E+04$ & $\mathrm{t}$ & $3.48 \mathrm{E}+15$ & $7.03 E+19$ & 6.656 & c. \\
\hline 13 & Brick & $1.06 \mathrm{E}+04$ & $\mathrm{t}$ & $3.90 \mathrm{E}+15$ & $3.93 E+19$ & 3.719 & c. \\
\hline 14 & Plastic & $9.50 \mathrm{E}++02$ & $\mathrm{t}$ & $9.83 E+15$ & $9.34 \mathrm{E}+18$ & 0.884 & c. \\
\hline 15 & Rubber & $2.31 \mathrm{E}+02$ & $\mathrm{t}$ & $5.38 \mathrm{E}+15$ & $1.24 \mathrm{E}+18$ & 0.118 & a. \\
\hline 16 & Glass & $9.66 \mathrm{E}+02$ & $\mathrm{t}$ & $3.63 E+15$ & $3.88 \mathrm{E}+18$ & 0.368 & c. \\
\hline \multicolumn{8}{|c|}{ Energy } \\
\hline 17 & Coal & $5.49 \mathrm{E}+15$ & $\mathrm{~J}$ & $6.72 \mathrm{E}+04$ & $3.52 \mathrm{E}+20$ & 33.278 & e. \\
\hline 18 & Gasoline & $4.70 \mathrm{E}+14$ & $\mathrm{~J}$ & $1.11 \mathrm{E}+05$ & $5.21 \mathrm{E}+19$ & 4.929 & e. \\
\hline 19 & Diesel oil & $8.39 E+13$ & $\mathrm{~J}$ & $8.90 \mathrm{E}+04$ & $7.47 \mathrm{E}+18$ & 0.707 & a. \\
\hline 20 & Electricity & $6.04 \mathrm{E}+14$ & $\mathrm{~J}$ & $2.69 \mathrm{E}+05$ & $1.62 \mathrm{E}+20$ & 15.361 & a. \\
\hline 21 & Natural gas & $5.11 \mathrm{E}+14$ & $\mathrm{~J}$ & $8.06 \mathrm{E}+04$ & $4.12 \mathrm{E}+19$ & 3.897 & a. \\
\hline \multicolumn{8}{|c|}{ Wastes } \\
\hline 22 & Waste water & $2.48 \mathrm{E}+13$ & $\mathrm{~J}$ & $1.12 \mathrm{E}+06$ & $2.65 E+19$ & & f. \\
\hline 23 & Construction waste & $3.96 \mathrm{E}+03$ & $\mathrm{t}$ & $3.01 \mathrm{E}+15$ & $2.67 \mathrm{E}+20$ & & f. \\
\hline 24 & Other waste & $6.19 E+03$ & $\mathrm{t}$ & $4.69 \mathrm{E}+15$ & $2.90 \mathrm{E}+19$ & & a. \\
\hline
\end{tabular}

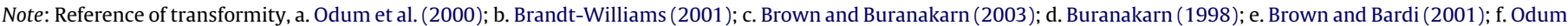
(1996) and h. Huang and Hsu (2003). All the values of tranformities are updated to the 15.83 E24 sej/yr global Emergy reference (Odum et al., 2000).

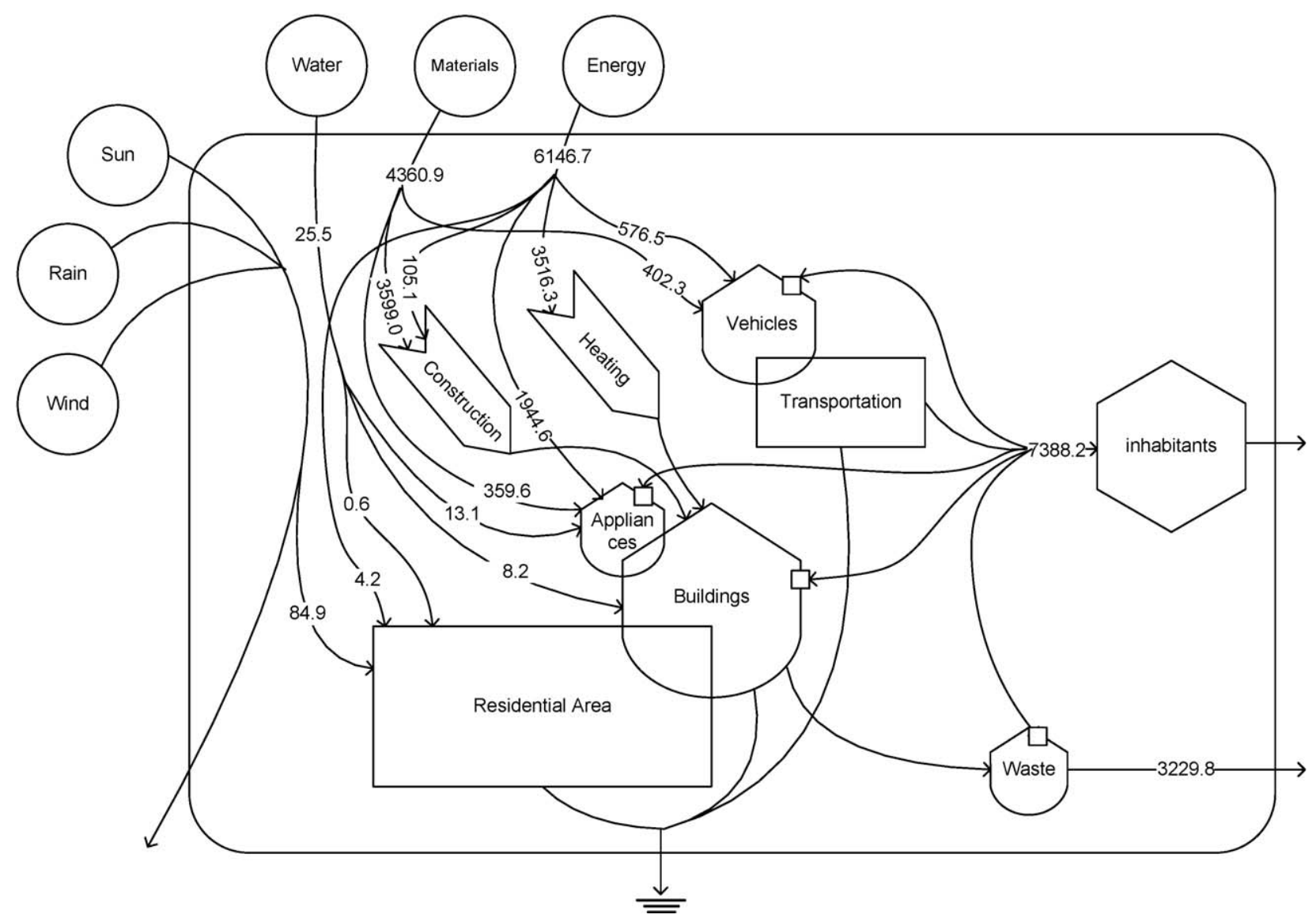

Fig. 3. Annual metabolic flow chart of TTY (E+17 sej/yr). 
Table 7

HEML index of TTY URA.

\begin{tabular}{|c|c|c|c|}
\hline Indices & & & Unit \\
\hline $\mathrm{X}_{1}$ & Household Empower & $1.72 \mathrm{E}+16$ & sej/yr \\
\hline $\mathrm{X}_{2}$ & URA environmental loading ratio (ELR) & 124.08 & $\mathrm{~N} / \mathrm{A}$ \\
\hline $\mathrm{X}_{3}$ & URA waste ratio (WR) & 38.05 & $\mathrm{~N} / \mathrm{A}$ \\
\hline $\mathrm{X}_{4 \mathrm{i}}$ & Gross household emissions & $1.82 \mathrm{E}+10,2.06 \mathrm{E}+08,6.67 \mathrm{E}+07,1.75 \mathrm{E}+06,1.51 \mathrm{E}+09$ & g pollutant $_{\text {i eq. } / y r}$ \\
\hline $\mathrm{X}_{5}$ & Emergy margin environmental impact & $3.69 \mathrm{E}+12$ & sej/emission impacts \\
\hline
\end{tabular}

Note: Where $\mathrm{i}=\mathrm{CO}_{2}$ eq., $\mathrm{SO}_{2}$ eq., $\mathrm{NO}_{3}{ }^{-}$eq., ethane eq., solid waste.

contributors to the POCP scores. The next significant impact is solid waste, whose amount in mass is $1.20 \mathrm{E}+08 \mathrm{~g} / \mathrm{yr}$ and the normalized value is 101.94. Following in degrees of significance are the impacts from the greenhouse gas (GWP) and the acidification matters (AP), while the NEP pollutants have the least impact.

For different sectors, Fig. 5 presents an overall picture of environmental impacts allocation among the three sectors of buildings, appliances and vehicles. Due to the large amount of resources used, the building sector consequently is a central source of pollutants. All of the largest environmental impact of every category is caused by construction. The vehicles bring the second largest impacts. The full result of HEML on TTY is summarized in Table 7.

\section{Discussion}

\subsection{Comparison}

To further demonstrate using HEML based metabolic evaluation on URAs, another sample URA, Zhongxin Sushe (ZXSS) near the inner city and of the average status of URAs in Beijing Municipality (BJ) were added for comparison. The data were collected through a similar survey and pulled from the Beijing Municipal Statistical Yearbook (2007) respectively.

The major differences between TTY and ZXSS lay on: (1) the distances to the city center; the distance from ZXSS to the city center is about $7.2 \mathrm{~km}$; (2) the volumes; the floor area of ZXSS is about $1 / 300$ of that of TTY; (3) the building types; the ZXSS was finished in two decades ago. Most of the buildings are lower than 6 stories; and (4) the space heating systems; a natural gas boiler is used in ZXSS instead of the regional coal-burning one in the TTY area. These differences brought on the dissimilarity of density and the behaviors of residents. The population per household in ZXSS is more than that of TTY because more percentage of old or retired people are living in ZXSS, while the density of buildings in ZXSS is less. Residents in ZSXX also drive less and use more public transportation.

Calculating results of these URAs are listed in Table 8. For easier understanding the comparison, the average status of $\mathrm{BJ}$ is chosen as

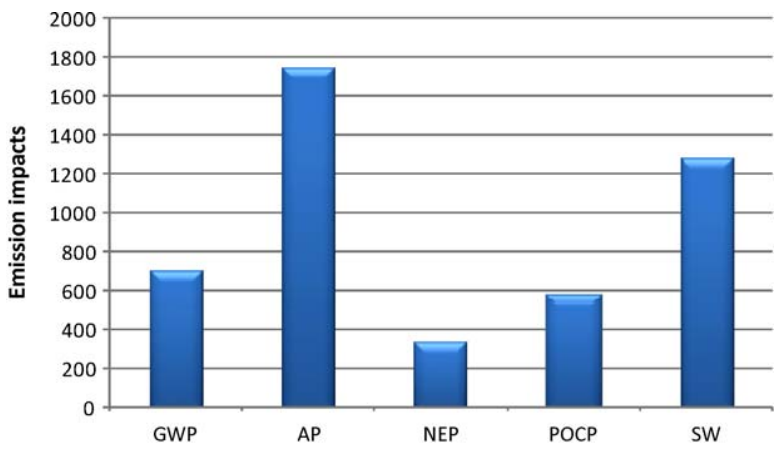

Fig. 4. Normalized result of environmental impacts. a reference benchmark. Deviations of the ELR and the pollutions of individual URA are expressed by their benchmark values, which reduces the rage of $X_{j i}$ to a standard one. The benchmark of BJ is associated with 0 . Thus, the deviations $D$ of individual URA reflect the "disadvantages or advantages" from the general local level.

$D=\frac{X_{j i}-X_{B i}}{X_{j i}}$

where $j=$ (TTY, ZXSS) and $i=(1,2,3,4,5)$.

A radar plot is used to interpret the deviations $D$ (Fig. 6). The range of radial axis is set from [ $-50 \%, 50 \%]$. The ELR and the six kinds of pollutions of TTY, ZXSS and Beijing city average are mapped to offer a general picture of their eco-environmental pressures. The value of Beijing city as benchmark is indicated at the middle circle. The calculated indicators of targeted URAs will fall near the benchmark circle. The external ones are worse and the internal ones are better than the local average. Additionally, the benchmark could be changed. For example, a current "best practice" URA could be used as benchmark for studying the mitigating alternatives of targeted URAs.

Considering the structure of emissions helps to better known of the differences among these URAs (Fig. 7). For the building sector, the differences of environmental impacts are caused by the various materials required for different building height. There are many more high-rise apartments in TTY, whereas the lowest building existing in the ZXSS. The planning regulation on height of URA contribute to this distinctness. This kind of scheme also influences the vehicles sector, as the residents in TTY have more requirements on mobility, which leading to the relatively higher owning rate of private cars inTTY and catalyzed by the longer distance to the inner city. The lack of public transportation accesses, such as metro stations or public buses lines around TTY further aggravates the ownership of private cars, which makes the impact of vehicles in TTY become more than two times as large as in ZXSS. For the appliances sector, the deviations are the smallest. For there are more aged people living in ZXSS, the owning rates and the using

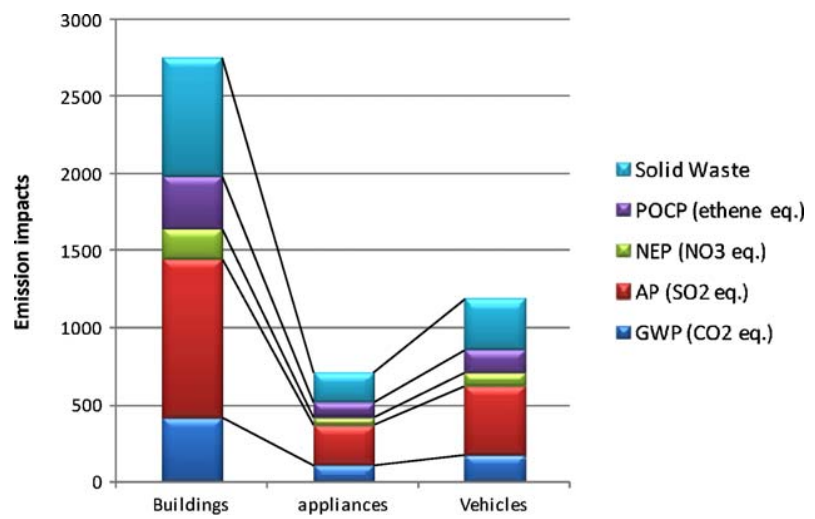

Fig. 5. Breakdown chart of pollutants from the buildings, appliances and vehicles. 
Table 8

Results of HEML indicators among TTY, ZXSS and BJ households.

\begin{tabular}{|c|c|c|c|c|c|c|c|c|}
\hline & Empower (sej/yr) & ELR (N/A) & WR (N/A) & $\begin{array}{l}\text { GWP } \\
\text { Emission impacts }\end{array}$ & $\begin{array}{l}\text { AP } \\
\text { Emission impacts }\end{array}$ & $\begin{array}{l}\text { NEP } \\
\text { Emission impacts }\end{array}$ & $\begin{array}{l}\text { POCP } \\
\text { Emission impacts }\end{array}$ & $\begin{array}{l}\text { SW } \\
\text { Emission impacts }\end{array}$ \\
\hline BJ & $1.06 \mathrm{E}+16$ & 104.60 & 39.09 & 403.48 & 997.59 & 191.86 & 332.03 & 736.15 \\
\hline ZXSS & $1.19 \mathrm{E}+16$ & 122.59 & 36.53 & 328.25 & 811.51 & 156.32 & 274.70 & 598.32 \\
\hline TTY & $1.72 \mathrm{E}+16$ & 124.08 & 38.05 & 705.42 & 1744.15 & 335.39 & 578.59 & 1287.79 \\
\hline
\end{tabular}

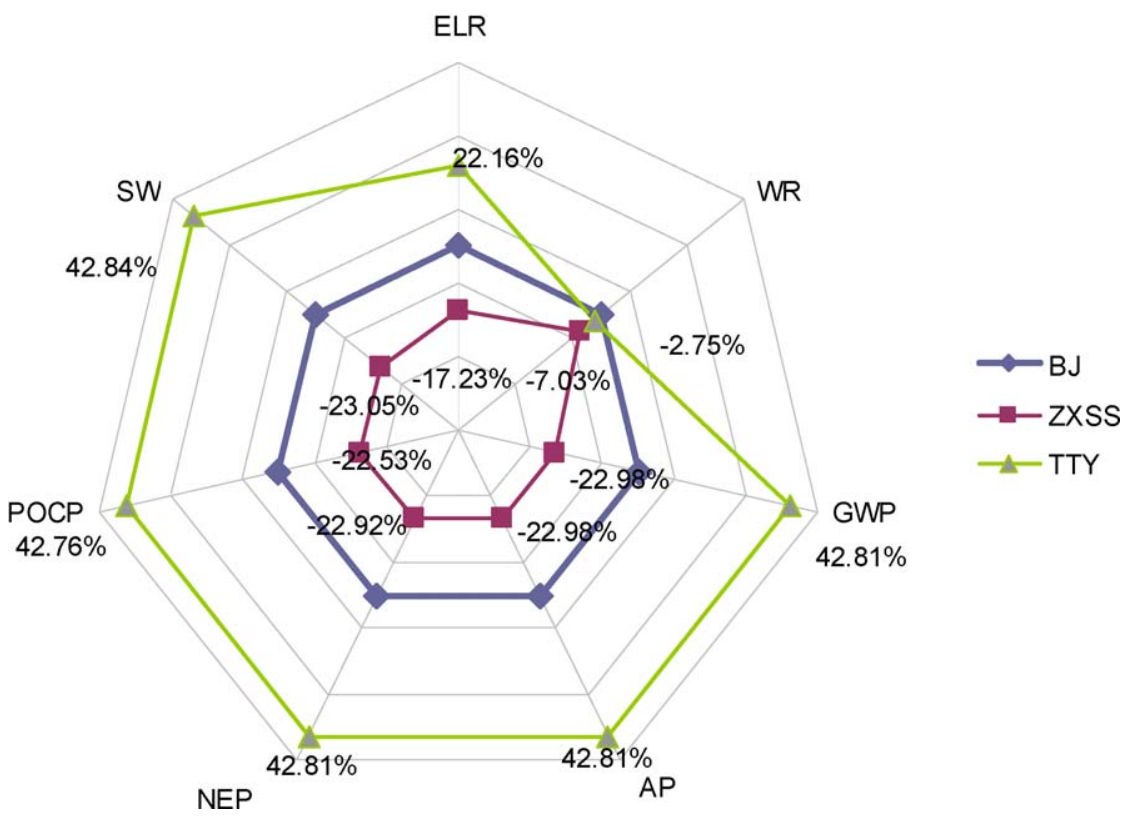

Fig. 6. Relative comparison, where the benchmark value of $\mathrm{BJ}=0 \%$.

intensity of appliances in ZXSS makes its environmental impacts be less than that of TTY and BJ average.

\subsection{The synthesized indicator}

From the above discussion, a general rule can be found, that the more raw materials and energy is used, the higher level of residential services is obtained, with heavier environmental loads and ecological pressures introduced to local and broader surroundings. Thus, the last indicator of HEML, Emergy margin environmental impact, could be adopted to determine the performance of household metabolic sustainability and providing a way for comparison among different URA systems.
Considering the substantial support and environmental loads together, when same volume of pollutants discharged, the URA with more Emergy inflows obtained by every household is more sustainable. Indeed, the margin value is the slope of URAs in the Emission-Emergy plot (Fig. 8). During the whole life cycles of production and consumption, although the households in TTY received more Emergy supporting their lives, they are also releasing greater gross pollutants than ZXSS and BJ. The Emergy margin environmental impact indicator is useful to identify a relevant ranking on the URA's sustainability. This synthesized indicator can be used to evaluate a migrating measure which would introduce any changes of the Emergy inflows and the environmental pollutants. Future studies could

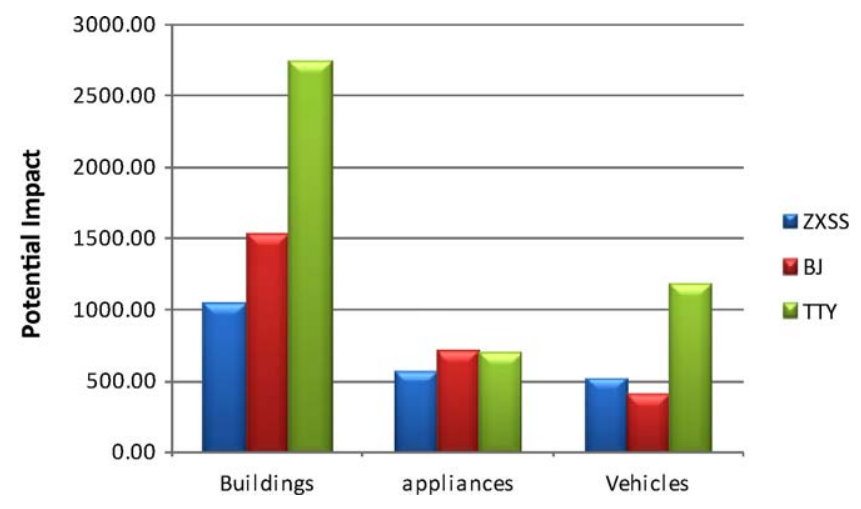

Fig. 7. Different composition of environmental impacts among TTY, ZXSS and BJ.

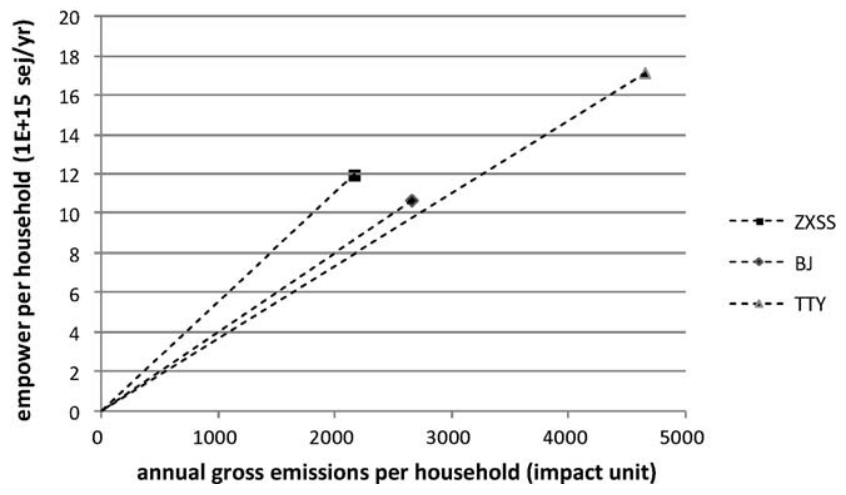

Fig. 8. Emission-Emergy plot of TTY, ZXSS and BJ. 
be carried out by selecting different benchmarks and marking off on this plot.

\section{Conclusion}

By reviewing and comparing different methodologies, we used the Hybrid Emergy-LCA (HEML) approach to assessing the conditions of metabolism in URAs. Based on the broader scope of the spatiality (regional and global) and the timeliness (full life cycles of products), the positive and the negative aspects of metabolism in URAs are investigated together and evaluated by objective values. Particularly, the emission impacts are recorded by their inventory masses, while their normalized values are also involved for the synthesized indicator Emergy margin environmental impact, which is representing the URAs' sustainability by their household metabolism states.

The HEML results of TTY in Beijing reveal that, the household Empower is $1.76 \mathrm{E}+16 \mathrm{sej} / \mathrm{yr}$. The URA Environmental Loading Ratio and WR is 127.58 and 39.62 respectively. The gross household emissions are $1.64 \mathrm{E}+09 \mathrm{~g} \mathrm{CO}$ eq./yr, $6.32 \mathrm{E}+06 \mathrm{~g} \mathrm{SO}_{2}$ eq./yr, $4.84 \mathrm{E}+06 \mathrm{~g} \mathrm{NO}_{3}{ }^{-}$eq./yr, $4.58 \mathrm{E}+05 \mathrm{~g}$ ethane eq./yr and $1.18 \mathrm{E}+08 \mathrm{~g}$ solid waste/yr. The prominent impact is a result of POCP matters. The Emergy margin environmental impact is $7.15 \mathrm{E}+13 \mathrm{sej} / \mathrm{emis}-$ sion impacts, which is $57.14 \%$ and $98.80 \%$ of that of the ZXSS and BJ average respectively.

The evaluating results of these three kinds of URAs in Beijing reflect that, currently, the main environmental impacts are all from the building sectors, accounting for half of the total impact around. The impact of vehicles differs, depending on the distance to job locations and the abundance of public transportation supply. While the appliance sectors are much similar across all URAs.

Based on the metabolic evaluation results, mitigation policies for improving the quality of living environment and enhancing the sustainability of URAs should focus on the building issues, e.g. using alternative and environmental-friendly materials, or increasing the life span of structures. Accessible and sufficient public transportation can support cutting down the environmental impacts effectively. All of the measures and improvements can be monitored and evaluated by the HEML index quantitatively.

\section{Acknowledgments}

Financial support for this research was provided by the Key Project of National Natural Science Foundation of China (No. 70433001) and Knowledge Innovation Project of Chinese Academy of Sciences (No. KZCX2-YW-324; KZCX2-YW-422). After all, the authors also would like to thank Dr. Erich W. Schienke at the Pennsylvania State University and Steve Mar at the University of Southern California for their very constructive and helpful comments on the manuscript.

\section{References}

Bai, X., 2007. Industrial ecology and the global impacts of cities. Journal of Industrial Ecology 11, 1-6.

Bakshi, B.R., 2002. A thermodynamic framework for ecologically conscious process systems engineering. Computers \& Chemical Engineering 26, 269-282.

Bargigli, S., Raugei, M., 2004. Comparison of thermodynamic and environmental indexes of natural gas, syngas and hydrogen production processes. Energy 29, 2145-2159.

Beijing Municipal Statistics Bureau (BMSB), 2007. Beijing Statistical Yearbook 2006. www.bjstats.gov.cn/tjnj/2006-tjnj/index-english.htm.

Brandt-Williams, S., 2001. Folio \#4 Emergy of Florida Agriculture. Center for Environmental Policy, Environmental Engineering Sciences, University of Florida, Gainesville.

Brown, M.T., Bardi, E., 2001. Folio \#3 Emergy of Ecosystems. Center for Environmental Policy, Environmental Engineering Sciences, University of Florida, Gainesville.
Brown, M.T., Buranakarn, V., 2003. Emergy indices and ratios for sustainable material cycles and recycle options resources. Resources, Conservation and Recycling 38, 1-22.

Brown, M.T., Herendeen, R.A., 1996. Embodied energy analysis and Emergy analysis: a comparative view. Ecological Economics 19, 219-235.

Brown, M.T., Ulgiati, S., 2002. Emergy evaluations and environmental loading of electricity production systems. Journal of Cleaner Production 10, 321-334.

Buranakarn, V., 1998. Evaluation of Recycling and Reuse of Building Materials Using the Emergy Analysis Method. Graduare School, University of Florida, Florida.

Chan, C.K., Yao, X., 2008. Air pollution in mega cities in China. Atmospheric Environment 42, 1-42.

Clark, W.C., 2003. Urban environments: battleground for global sustainability. Environment 45, 1-11.

Costanza, R., 2007. Quality of life: an approach integrating opportunities, human needs, and subjective well-being. Ecological Economics 61, 267-276.

Decker, E.H., Elliott, S., Smith, F.A., Blake, D.R., Rowland, F.S., 2000. Energy and material flow through the urban ecosystem. Annual Review of Energy and the Environment 25, 685-740.

Dincer, I., Rosen, M.A., 2005. Thermodynamic aspects of renewables and sustainable development. Renewable and Sustainable Energy Reviews 9, 169-189.

Distaso, A., 2007. Well-being and/or quality of life in EU countries through a multidimensional index of sustainability. Ecological Economics 64, 163-180.

Ferng, J.-J., 2005. Local sustainable yield and embodied resources in ecological footprint analysis. Ecological Economics 53, 415-430.

Hau, J.L., 2002. Integrating life cycle assessment. In: Exergy and Emergy analysis, Department of Chemical Engineering, The Ohio State University.

Huang, S.-L., Hsu, W.-L., 2003. Materials flow analysis and Emergy evaluation of Taipei's urban construction. Landscape and Urban Planning 63, 61-74.

Huang, S.-L., Lai, H.-Y., Lee, C.-L., 2001. Energy hierarchy and urban landscape system. Landscape and Urban Planning 53, 145-161.

ISO 14040, 1997. Environmental Management - Life Cycle Assessment - Principles and Framework. The International Organization for Standardization.

Janssen, G.M.T., 2007. Reducing greenhouse gas emissions by mega-recycling in urban renewal. In: International Conference on Climate Change 2007, Hong Kong, China.

Jogensen, S.E., Fath, B.D., 2004. Application of thermodynamic principles in ecology. Ecological Complexity 1, 267-280.

Kennedy, C., Cuddihy, J., Engel-Yan, J., 2007. The changing metabolism of cities. Journal of Industrial Ecology 11, 43-59.

Kotaji, S., Schuurmans, A., 2003. Life-cycle assessment in building and construction: a state-of-the-art report. SETAC.

Li, D., Wang, R., Zhou, C., 2009. Leap based comprehensive scenario analysis of Emergy evaluation on urban residential area (in Chinese, with English abstract). Journal of the Graduate School of the Chinese Academy of Sciences $26,72-82$.

Liu, T., Hu, D., 2006. Environmental impact of residential building construction in Beijing: 1949-2003: assessing the construction materials' environmental impact by LCA (in Chinese, with English abstract). Journal of the Graduate School of the Chinese Academy of Sciences 23, 231-241.

Ludovisi, A., Pandolfi, P., Illuminata Taticchi, M., 2005. The strategy of ecosystem development: specific dissipation as an indicator of ecosystem maturity. Journal of Theoretical Biology 235, 33-43.

Makarieva, A.M., Gorshkov, V.G., Li, B.-L., 2008. Energy budget of the biosphere and civilization: rethinking environmental security of global renewable and nonrenewable resources. Ecological Complexity 5, 281-288.

McMahon, S.K., 2002. The development of quality of life indicators-a case study from the city of Bristol, UK. Ecological Indicators 2, 177-185.

Meillaud, F., Gay, J.-B., Brown, M.T., 2005. Evaluation of a building using the Emergy method. Solar Energy 79, 204-212.

Ness, B., Urbel-Piirsalu, E., Anderberg, S., Olsson, L., 2007. Categorising tools for sustainability assessment. Ecological Economics 60, 498-508.

Odum, H.T., 1996. Environmental Accounting: Emergy and Environmental Decision Making. Wiley, New York.

Odum, H.T., Mark, T., Brown, Brandt-Williams, S., 2000. Folio \#1 introduction and global budget. In: Environmental Engineering Sciences, Center for Environmental Policy, University of Florida, Gainesville.

Pataki, D.E., Emmi, P.C., Forster, C.B., Mills, J.I., Pardyjak, E.R., Peterson, T.R., Thompson, J.D., Dudley-Murphy, E., 2009. An integrated approach to improving fossil fuel emissions scenarios with urban ecosystem studies. Ecological Complexity $6,1-14$.

Pizzigallo, A.C.I., Granai, C., Borsa, S., 2008. The joint use of LCA and Emergy evaluation for the analysis of two Italian wine farms. Journal of Environmental Management 86, 396-406.

Pulselli, R.M., Simoncini, E., Pulselli, F.M., Bastianoni, S., 2007. Emergy analysis of building manufacturing, maintenance and use: Em-building indices to evaluate housing sustainability. Energy and Buildings 39, 620-628.

Raine, A., Foster, J., Potts, J., 2006. The new entropy law and the economic process. Ecological Complexity 3, 354-360.

Raugei, M., Bargigli, S., Ulgiati, S., 2005. A multi-criteria life cycle assessment of molten carbonate fuel cells. International Journal of Hydrogen Energy 30, 123130.

Reddy, B.V.V., Jagadish, K.S., 2003. Embodied energy of common and alternative building materials and technologies. Energy and Buildings 35, 129-137.

Ritthoff, M., Rohn, H., Liedtke, C., 2002. Calculating MIPS, Resource Productivity of Products and Services. Wuppertal Institute for Climate, Environment and Energy, Wuppertal, Germany. 
Rosen, M.A., 2002. Assessing energy technologies and environmental impacts with the principles of thermodynamics. Applied Energy 72, 427-441.

Ryan, J.G., Ludwig, J.A., McAlpine, C.A., 2007. Complex adaptive landscapes (cal): a conceptual framework of multi-functional, non-linear ecohydrological feedback systems. Ecological Complexity 4, 113-127.

Scienceman, D.M., 1997. Letters to the editor: Emergy definition. Ecological Engineering 9, 209-212.

Shen, L., Cheng, S., Gunson, A.J., Wan, H., 2005. Urbanization, sustainability and the utilization of energy and mineral resources in China. Cities 22, 287-302.

Tainter, J.A., 2006. Social complexity and sustainability. Ecological Complexity 3, 91-103.

Thormark, C., 2002. A low energy building in a life cycle-its embodied energy, energy need for operation and recycling potential. Building and Environment 37, 429-435.
Ulgiati, S., Raugei, M., Bargigli, S., 2006. Overcoming the inadequacy of singlecriterion approaches to life cycle assessment. Ecological Modelling 190, 432-442.

United Nations Statistics Division (UNSD), 2006. Demographic and Social Statistics. unstats.un.org/unsd/demographic/sconcerns/densurb/densurb2.htm.

United States Environmental Protection Agency (USEPA), 2006. Life Cycle Assessment: Principles and Practice. www.epa.gov/ORD/NRMRL/lcaccess.

Wolman, A., 1965. The metabolism of cities. Scientific American 213, 90.

Xiao, R.-b., Ouyang, Z.-y., 2007. Spatial pattern of impervious surfaces and their impacts on land surface temperature in Beijing, China. Journal of Environmental Sciences 19, 250-256.

Yang, J., Xu, C., Wang, R., 2002. Methodology and Application of Life Cycle Assessment (in Chinese). China Meteorological Press, Beijing.

Zhang, Y., Yang, Z., Yu, X., 2006. Measurement and evaluation of interactions in complex urban ecosystem. Ecological Modelling 196, 77-89. 